\title{
A importância do diagnóstico de tuberculose em pediatria: um relato de caso
}

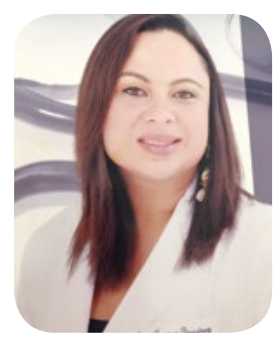

\section{INTRODUÇÃO}

A Organização Mundial de Saúde (OMS) indica que em 2016 tiveram aproximadamente 1 milhão de casos de tuberculose (TB) na população infantil mundial e a doença foi responsável por 130 mil mortes naquele ano, o que faz com que a TB seja uma das 10 principais causas de óbito em crianças no mundo. No Brasil, de acordo com o Sistema de Informação de Agravos de Notificação (SINAN), em 2015, foram registrados 83.617 casos de TB, dos quais $7.106(8,5 \%)$ ocorreram em menores de 19 anos. ${ }^{1}$

A doença pulmonar e a adenopatia intratorácica associada é a apresentação mais frequente de TB em crianças. ${ }^{2}$ Contudo, pode haver doença extrapulmonar, com diversas outras apresentações clínicas, a depender do sítio de acometimento. Sendo que os mais comuns são: ganglionar e sistema nervoso central. ${ }^{3}$

\section{CASO CLÍNICO}

O paciente K.C.S., 11 anos, estudante, sexo masculino, previamente hígido, deu entrada no pronto atendimento pediátrico do Hospital Santa Izabel em 07 de julho de 2016, com relato de febre diária iniciada há 14 dias da admissão. A febre não possuía predileção de horário, a temperatura máxima era de $39^{\circ} \mathrm{C}$, em média 2 a 3 picos diários, cursava com sudorese no momento da febre e cedia ao uso de dipirona. Referia tosse produtiva esporádica e perda ponderal, aproximadamente, de 4 quilos no último mês. Negava vômitos, diarreia, lesões de pele ou qualquer outra queixa adicional relacionada ao quadro. Fez uso no período de amoxicilina por 7 dias, além de sintomáticos. Negava viagens recentes ou contato com portador de TB. Negava patologias prévias.

Ao exame físico, o menor encontrava-se com estado geral e nutricional preservados, o padrão respiratório era adequado para a idade, bem como a ausculta

\author{
Joana Moreira Queiroz ${ }^{1}$, Rita Mira ${ }^{1}$
}

pulmonar era normal. Apresentava linfonodos cervicais, inguinais e axilares, o maior medindo $1 \mathrm{~cm}$, de característica fibroelástica, móvel e indolor. O exame segmentar adicional não apresentava alterações.

$\mathrm{Na}$ admissão, apresentava exames laboratoriais sem achados significativos e radiografia $(\mathrm{Rx})$ de tórax com adensamento hilar, conforme Figura 1.

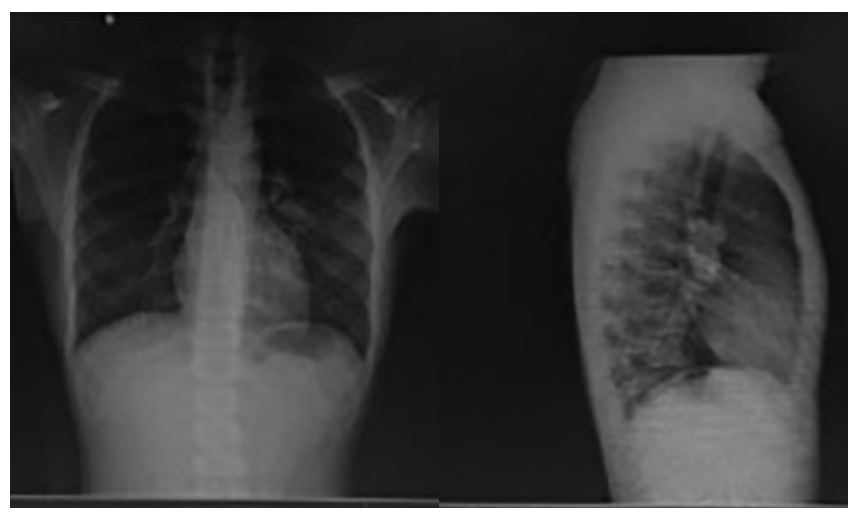

Figura 1. Rx de tórax PA e perfil

Foi solicitado internamento hospitalar para tratamento e investigação diagnóstica, além de ter sido introduzido na admissão cefuroxima e sintomáticos.

Inicialmente, a criança foi abordada como febre de origem indeterminada, foram solicitados os seguintes exames: hemocultura, baciloscopia do escarro, cultura do escarro, sorologias, teste tuberculínico (PPD), ecocardiograma transtorácico (TT), ultrassonografia (US) de abdômen e tomografia (TC) de tórax.

Os exames revelaram: hemocultura negativa, baciloscopia do escarro negativa (2 amostras), cultura do escarro negativa, PPD não reator, Anti-HIV 1 e 2 não reagente, IgM toxoplasmose não reagente, IgG toxoplasmose não reagente, IgG citomegalovirus reagente, IgM citomegalovírus não reagente, IgM Epstein 
Barr não reagente, IgG Epstein Barr reagente, USG de abdômen normal, ecocardiograma TT normal e TC de tórax apresentou formação com densidade de partes moles peri-hilar à esquerda, com margens irregulares e lobuladas, de limites imprecisos, sem nítido plano de clivagem com a região subaórtica, nódulo com densidade de partes moles e margens lobuladas no lobo inferior do pulmão esquerdo, medindo cerca de 1,0 $\mathrm{x}$ $0,8 \mathrm{~cm}$ em seus maiores eixos axiais, além de linfonodomegalias em cadeia subaórtica, subcarinal e hilar à esquerda.

Diante dos achados obtidos na TC de tórax, a hipótese mais provável naquele momento era de doença neoplásica, sendo que as patologias de origem inflamatória/ infecciosa faziam parte do diagnóstico diferencial.

O menor foi então submetido à toracoscopia, que evidenciou linfonodomegalia mediastinal, sendo realizada linfadenectomia mediastinal, encaminhado material para biópsia, pesquisa de BAAR e cultura.

A despeito do tratamento instituído na admissão, o paciente manteve febre diária, sem mudança do padrão da mesma, foi verificada a manutenção da imagem radiológica e não houve piora clínica neste período. Fez uso de cefuroxima por 10 dias.

A conclusão da biópsia foi linfadenite crônica granulomatosa, a baciloscopia linfonodal foi negativa e a cultura do linfonodo houve crescimento de Mycobacterium tuberculosis, sensível à isoniazida, etambutol, estreptomicina e rifampicina.

Foi iniciado o esquema básico indicado para tratamento de tuberculose na faixa etária pediátrica, conforme protocolo do Ministério da Saúde do Brasil (MS), com rifampicina, isoniazida, pirazinamida e etambutol, por 2 meses, seguido de rifampicina e isoniazida por mais 4 meses. $^{4}$

A criança cursou com boa evolução, não evidenciou efeitos colaterais relacionados ao uso do tratamento instituído. Após finalizar o tratamento para TB, realizou nova TC de tórax, com resolução completa da imagem.

\section{DISCUSSÃO}

O grande desafio relacionado à TB na faixa etária pediátrica é o seu diagnóstico, que é prejudicado pela ausência de exame específico que possa ser considerado padrão-ouro. As técnicas diagnósticas classicamente utilizadas em adultos apresentam baixa sensibilidade e especificidade em crianças e a confirmação pela identificação bacteriológica nem sempre é viável ${ }^{5}$. Como TB pulmonar em crianças tipicamente apresenta doença pulmonar paucibacilar e não cavitária, a confir- mação bacteriológica é em menos de $50 \%$ das crianças maiores e $75 \%$ dos lactentes ${ }^{6}$. Destaca-se que a correta caracterização da doença na fase precoce é extremamente importante para reduzir a morbidade dessa infecção. O diagnóstico tardio e, consequentemente, a instituição de terapêutica adequada de forma tardia estão intimamente relacionados ao aumento não somente da morbidade, como da mortalidade decorrente da $\mathrm{TB}^{7}$.

O diagnóstico de TB em pediatria é frequentemente baseado na presença da tríade clássica: contato próximo recente com um portador de TB, PPD reator e achados sugestivos no Rx de tórax ou exame físico/ história clínica ${ }^{8}$. Em 2017, a Sociedade Americana de Doenças Infecciosas inclui o IGRA (interferon-gamma release assays) como mais um método aliado, a fim de contribuir no diagnóstico de TB' .

O MS emprega como auxílio no diagnóstico de TB em criança abaixo de 10 anos ou adolescentes com bacilosocopia negativa, o sistema baseado em pontos, conforme o quadro 1. De acordo com a pontução baseada nos critérios utilizados, a suspeita de tuberculose é: muito provável, se apresentar maior ou igual a 40 pontos, possível se apresentar entre 30 e 35 pontos e pouco provável se apresentar igual ou inferior a 25 pontos $^{10}$.

Quadro 1. Sistema de pontuação para diagnóstico de TB pulmonar em crianças (menores de 10 anos) e em adolescentes (com BAAR negativo)' [B].

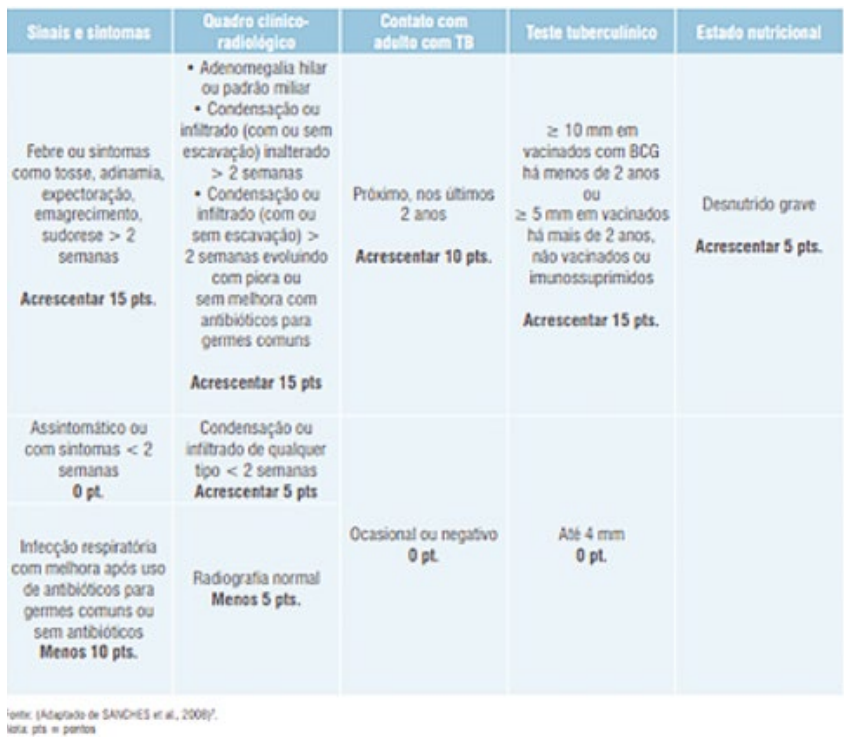


Logo, a partir do exposto, a tuberculose é uma realidade atual em pediatria, inclusive com risco de óbito, conforme os dados estatísticos. Diante da dificuldade do diagnóstico inerente a esta faixa etária, é necessário que esta afecção seja considerada diante das possibilidades durante a prática clínica, principalmente pelo fato de ser uma doença com apresentação clínica variada e não específica. Além disso quanto mais precoce é o seu reconhecimento, com consequente instituição da terapêutica adequada, melhor resultado e desfecho final terá o paciente.

\section{REFERÊNCIAS}

1. Tuberculosis in pediatricpatients: howhasthediagnosisbeenmade?.Rev Paul Pediatr. 2017;35(2):165170.

2. Cruz AT, Starke JR. Clinical manifestations of tuberculosis in children. PaediatrRespir Rev 2007; 8:107.

3. Mandalakas AM, Starke JR. Current concepts of childhood tuberculosis. Semin Pediatr Infect Dis 2005; 16:93.

4. BRASIL. Ministério da Saúde. Secretaria de Vigilância em Saúde. Nota técnica sobre as mudanças no tratamento da tuberculose no Brasil para adultos e adolescentes. Brasília: Ministério da Saúde, 28 ago. 2009.

5. Marais BJ, Pai M. Recent advances in the diagnosis of childhood tuberculosis. Arch. Dis. Child. 2007;92:446-52.

6. American Academy of Pediatrics. Tuberculosis. In: Red Book: 2015 Report of the Committee on Infectious Diseases, 30th ed, Kimberlin DW, Brady MT, Jackson MA, Long SS (Eds), American AcademyofPediatrics, Elk Grove Village, IL 2015. p.805.

7. Perez-Velez CM, Marais BJ. Tuberculosis in children. N Engl J Med 2012; 367:348

8. Lawn SD, Zumla Al. Tuberculosis. Lancet. 2011;378:57-72.

9. Lewinsohn DM, Leonard MK, LoBue PA, et al. Official American Thoracic Society/Infectious Diseases Society of America/Centers for Disease Control and Prevention Clinical Practice Guidelines: Diagnosis of Tuberculosis in Adults and Children. Clin Infect Dis 2017; 64:111.

10. SÁNCHEZ, G. M. et al. Formas clínicas de latuberculosis infantil: Hospital Roberto delRío. 1989-2005. RevChilEnfRespir, Chile, v. 24, p. 101-105, 2008.

1- Serviço de Pediatria do HSI

Endereço para correspondência:

joanamoreiraqueiroz@yahoo.com.br 
Referência em

NEUROLOGIA E OTORRINO

dentre 39 especialidades.

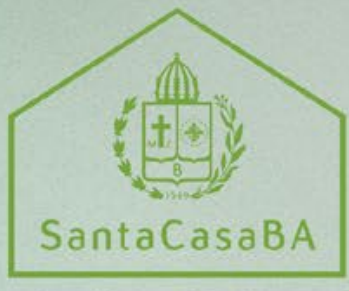

Hospital

SANTA IZABEL

Santa Izabel, o Hospital da Santa Casa da Bahia.

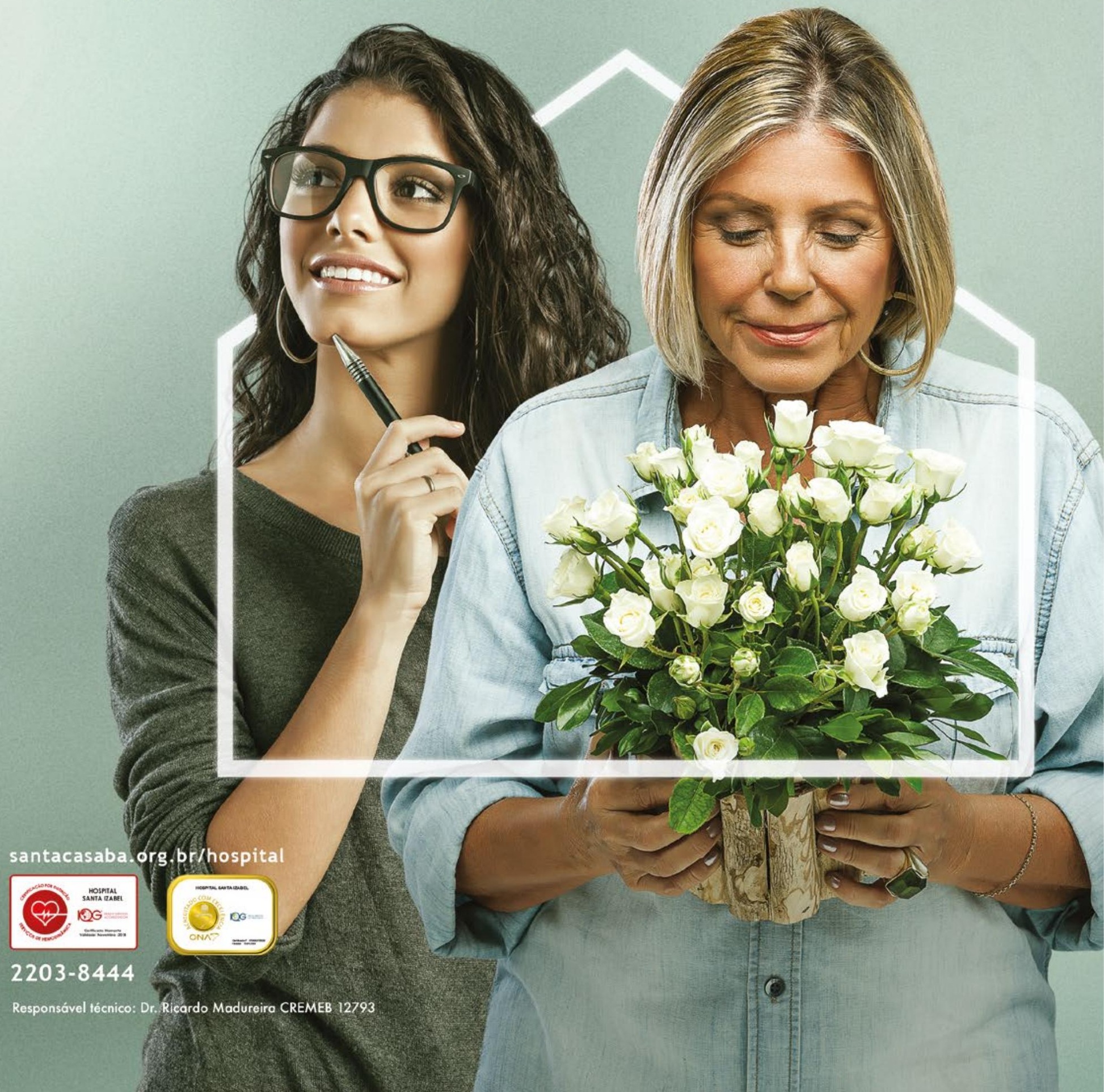

